Data represented either as the median (25th-75th percentile) or as the frequency a: MannWhitney test b: Pearson Chi-Square test, CQR, Compliance Questionnaire on

\section{FRI0615 EVALUATION OF COMPLIANCE AND RELATED FACTORS IN COLCHICINE TREATMENT IN FAMILIAL MEDITERRANEAN FEVER PATIENTS}

Emre Tekgoz ${ }^{1}$, Seda Colak ${ }^{1}$, Fatma IIlknur Cinar ${ }^{2}$, Sedat Yilmaz ${ }^{1}$ Muhammet Çınar ${ }^{1} .{ }^{1}$ University of Health Sciences, Gulhane Faculty of Medicine, Department of Internal Medicine, Division of Rheumatology, Ankara, Turkey, ${ }^{2}$ University of Health Sciences, Gulhane Faculty of Nursing, Department of Internal Medicine Nursing, Ankara, Turkey

Background: Familial Mediterranean Fever (FMF) is an autoinflammatory disease requiring long-term treatment. Increasing the compatibility with colchicine treatment in patients with FMF is the first step for preventing amyloidosis. Patients' beliefs about medicines and treatment may affect treatment adherence and treatment success.

Objectives: The aim of this study was to determine adherence to colchicine treatment and related factors in FMF patients. In addition, patients beliefs about colchicine, which are one of the important factors affecting the treatment adherence of patients, were evaluated.

Methods: Total of 179 patients with FMF was included in this study. The demographic and clinical features and MEFV gene mutations were recorded. The treatment adherence of the patients was assessed using by Compliance Questionnaire on Rheumatology (CQR). The Beliefs About Medicines Questionnaire (BMQ-T) was used to assess patient's beliefs about colchicine. The relationship between compliance of treatment and clinical characteristics of patients were assessed.

Results: One hundred thirteen $(63.1 \%)$ of the patients were male. The mean age of patients was $34.5 \pm 12.7$ years and mean delay in diagnosis was $6.7 \pm 8.4$ years. The mean dose of colchicine was $1.37 \pm 0.43$ $\mathrm{mg} /$ day and, the percentage of patients using colchicine regularly was $66.5 \%$. Adherence to treatment was higher in patients with concomitant diseases than those without comorbidities $(p=0.028)$. In addition, treatment compliance was higher in married patients compared to single patients $(p=0.013)$. The colchicine dose used in compatible patients was higher than in non-compatible patients $(p=0.033)$ (Table 1). We also found that as the BMQ-T Specific Necessity scores increased, compliance with treatment increased. On the other hand, as the BMQ-T General Overuse and General Harm scores increased, non-compliance with treatment increased (Table 2).

Table 1. Relationships between socio-demographic and clinical characteristics of patients and CQR score $(\mathrm{n}=179)$

\begin{tabular}{lccc}
\hline Characteristics & \multicolumn{3}{c}{ CQR score } \\
\hline \multicolumn{1}{l}{$\mathbf{2 0 0} \mathbf{n = 2 9}$} & $<\mathbf{8 0 \%} \mathbf{n = 1 5 0}$ & $\mathbf{p}$ \\
\hline Age (years) median (25th-75th percentile) & $37.0(28.5-44.5)$ & $29.0(24.0-44.0)$ & $0.099^{\mathrm{a}}$ \\
Gender (n,\%) & $15(13.3)$ & $98(86.7)$ & $0.164^{\mathrm{b}}$ \\
Male & $14(21.2)$ & $52(78.8)$ & \\
Female & & & \\
Marital status, (n,\%) & $21(22.8)$ & $71(77.2)$ & $\mathbf{0 . 0 1 3 ^ { \mathrm { b } }}$ \\
Married & $8(9.2)$ & $79(90.8)$ & \\
Single/widowed/divorced & $12(26.7)$ & $33(73.3)$ & $\mathbf{0 . 0 2 8 ^ { \mathrm { b } }}$ \\
Comorbidities, (n,\%) & $17(12.7)$ & $117(87.3)$ & \\
Yes & & & \\
No & $3.0(0.5-10.0)$ & $3.0(1.0-9.0)$ & $0.920^{\text {a }}$ \\
Delay of diagnosis (years) & & & \\
Median (25th-75th percentile) & &
\end{tabular}

Rheumatology

Table 2. Beliefs about Medicines Questionnaire Scale Scores in Adherent and Nonadherent Patients.

\begin{tabular}{lcccc}
\hline \multicolumn{5}{c}{ CQR score } \\
\hline Variable & \multicolumn{5}{c}{ Discontinuous } \\
\hline & $\mathbf{8 0}=\mathbf{n}=$ & $<80 \% \mathrm{n}=150$ & $\mathbf{Z}$ & $\mathrm{p}$ \\
BMQ-T-Specific & $4.8(4.1-5.0)$ & $3.8(3.35-4.25)$ & -5.260 & $<$ \\
Necessity & & & & $\mathbf{0 . 0 0 1}$ \\
BMQ-T-Specific Concerns & $2.8(2.2-3.8)$ & $2.8(2.4-3.6)$ & -0.100 & 0.920 \\
BMQ-T-General Overuse & $2.25(1.75-$ & $2.75(2.25-$ & -2.936 & $\mathbf{0 . 0 0 3}$ \\
& $2.63)$ & $3.25)$ & & \\
BMQ-T-General Harm & $1.75(1.38-$ & $2.38(2.0-3.0)$ & -3.212 & $\mathbf{0 . 0 0 1}$ \\
& $2.63)$ & & & \\
\hline
\end{tabular}

Z; Mann-Whitney test, Data represented as median (25th-75th percentile, CQR; Compliance Questionnaire on Rheumatology

Conclusion: In patients with FMF, it is important to evaluate the compliance with the treatment due to the importance of colchicine to prevent amyloidosis that may occur in patients without treatment. As this study shows it is also important to determine patients' beliefs about medicine in terms of their influence on patients' compliance with treatment.

Disclosure of Interests: : None declared

DOI: 10.1136/annrheumdis-2019-eular.3545

\section{FRI0616 ANAKINRA TREATMENT IN RECURRENT PERICARDITIS: SINGLE CENTER EXPERIENCE}

Zeynep Toker Dincer, Osman Corbali, Serdal Ugurlu, Huri Ozdogan. University of Istanbul-Cerrahpasa, Division of Rheumatology, Department of Internal Medicine, Istanbul, Turkey

Background: Recurrent pericarditis (RP), however the etiology is unknown in the majority, may be observed in autoinflammatory diseases such as familial Mediterranean fever (FMF) and tumor necrosis factor receptor-1 associated periodic syndrome (TRAPS). Colchicine has long been used to treat pericarditis related to FMF as well as patients with idiopathic recurrent pericarditis (IRP) (1). Alternative treatments have been reported for cases with colchicine resistant RP.Objectives:

Objectives: The aim is to present our data regarding anakinra treatment in recurrent pericarditis either related to FMF or idiopathic, who are resistant to colchicine.

Methods: Patients who had recieved anakinra with a diagnosis of recurrent pericarditis either idiopathic or secondary to FMF followed in our autoinflammatory disease center between 2014-2018 are evaluated retrospectively. From patients' files, demographic and clinical features, response to other treatment approaches such as NSAID, corticosteroid, colchicine, were evaluated. All patients have been genetically screened for monogenic autoinflammatory diseases (MEFV, TRAPS, MVK, NLRP3, NOD2). Patients who had at least 3 attacks were administered anakinra $100 \mathrm{mg} /$ day. Therapeutic efficacy, as well as side effect profile of anakinra is also assessed.

Results: There were 5 patients ( 3 male and 2 female) with the diagnosis of RP, 1 was related to FMF and 4 were idiopathic. The mean age of

Table 1. Demographic features and treatment response during anakinra therapy

\begin{tabular}{|c|c|c|c|c|c|c|c|c|c|}
\hline $\begin{array}{l}\text { Patient } \\
\text { ID \# }\end{array}$ & Age & Sex & Diagnosis & $\begin{array}{c}\text { Duration of pericarditis } \\
\text { follow-up (mo) }\end{array}$ & Prior medications & $\begin{array}{c}\text { Number of recurrences } \\
\text { before anakinra }\end{array}$ & $\begin{array}{c}\text { Anakinra treatment } \\
\text { duration }(\mathrm{mo})\end{array}$ & $\begin{array}{l}\text { Time to corticosteroid } \\
\text { discontinuation }(\mathrm{mo})\end{array}$ & $\begin{array}{c}\text { Number of recurrences after } \\
\text { daily dose of anakinra }\end{array}$ \\
\hline $1^{*}$ & 23 & $M$ & IRP & 129 & $\begin{array}{c}\text { Colchicine, } \\
\text { NSAIDs, CS, HCQ }\end{array}$ & 6 & 52 & 9 & No \\
\hline 2 & 32 & $\mathrm{~F}$ & IRP & 128 & $\begin{array}{l}\text { Colchicine, } \\
\text { NSAIDs }\end{array}$ & 7 & 4 & NA & No \\
\hline $3^{*}$ & 40 & $\mathrm{~F}$ & IRP & 21 & Colchicine, CS & 6 & 8 & 1 & No \\
\hline 4 & 20 & M & IRP & 11 & Colchicine, CS & 3 & 8 & 2 & No \\
\hline 5 & 25 & M & FMF & 30 & Colchicine, CS & 5 & 15 & 1 & No \\
\hline
\end{tabular}

F: Female, M: Male, CS: Corticosteroid, HCQ: Hydroxychloroquine, NA: Not applicable

*Dose tapering was unsuccessful in these patients 